\title{
Ad census accipiendos de ciudades vasconas y vardulas y la legatio censualis de un pamplones
}

JUAN JOSÉ SAYAS

\section{A. AD CENSUS ACCIPIENDOS}

1. Cuando en el 1873 , D. Detlefsen realizó su estudio sobre la información proporcionada por Plinio en su Historia Natural respecto de los pueblos y comunidades de la Tarraconense, ya prestó atención a la inscripción (CIL, VI, 1643) encontraba en Roma en la que se especifica que un tal Caius Mocconius Verus había realizado un censo en XXIIIIIIcivitatium Vasconum et Vardul(I)orum '.

La inscripción ha dado pie a diversas consideraciones respecto de la época, origen y procedencia del personaje en cuestión, sobre el censo y las ciudades implicadas en el mismo.

El desarrollo de la inscripción no aporta ningún dato fehaciente mediante el cual pueda atribuírsele una fecha concreta. Sólo por indicios indirectos, y no sin que éstos den origen a distintas propuestas, la incrip-

' ClL, VI, 1643: C. Mocconio/C. f. Fab. Ver/o// praetori, legato pro /pr// provinciae Achaiae t/r. pl.J/ q. urbano III vir. capit/ali]/ tribuno laticlavio //eg//VII gemin. at census accipilen/ / dos civitatium XXIIIII] / Vasconum et Vardul(I)orum / vixit annis XXXVI/ ex testamento. D. DETLEFSEN, “Die geographie der tarraconensichen provinz bei Plinius (N.H., III, 18-30.76-79. IV,110-112)", Philologus, 32, 1873, pág. 643; M. MARCHETtI, Diz. Ep., III, pág. 815. Esta inscripción está recogida también por G. Alföldy, Fasti Hispanienses, Wiesbaden, 1969, págs. 128-129; J.M. RoLDAN, Hispania y el ejército romano. Salamanca 1974, pág. 322, pág. 485 núm. 796. 
ción puede situarse con cierta probabilidad, en un espacio temporal relativamente corto. En este sentido conviene significar que como el personaje en cuestión fue "tribunus" de la legio VII Gemina, la inscripción, naturalmente, es posterior al 68, fecha de la creación de esta legión ${ }^{2}$ y posterior también al 74 , que es la fecha que se acostumbra a proponer para su instalación definitiva en Hispania ${ }^{3}$.

Teniendo en cuenta que la inscripción presenta un orden decreciente en la ocupación de los cargos, E. Groag ${ }^{4}$ toma en consideración el hecho de que Caius Mocconius Verus haya ocupado el cargo de «tribunus legionis" con anterioridad a uno de los correspondientes al vigintivirato, y no al revés, para de ello concluir, de una manera general, que la inscripción en cuestión convendría situarla cronológicamente en la segunda mitad del siglo I. Otros ${ }^{5}$, que también tienen en consideración la relación existente para los miembros de la clase senatorial entre el tribunado y el vigintivirato, piensan, por el contrario, que la inscripción parece corresponder a la época de Adriano (117-138) o de Antonino Pio (138-161).

2. Se piensa, con bastante probabilidad, que Caius Mocconius Verus era originario del norte de África ${ }^{6}$. Pertenecía a la clase senatorial y, en razón a ello, siguió el "cursus honorum» correspondiente a los miembros de esta clase ${ }^{7}$. Además de algunos cargos de menor entidad, la

\footnotetext{
"Ver al respecto A. GARCiA y Bellioo, "Nacimiento de la Legio VII Gemina", Legio VII Gemina. León 1970, pág. 305 ss.

${ }^{3}$ Ver RItTERLING, R.E., XII, 1629 ss.

${ }^{4}$ E. Groag, Die römischen Reichsbeamten von Achaia bis Diokletian. Viena 1939, pág. 101. También Th. MOMmSEN (Droit public romain, trad. franc. I, 2, pág. 202) pensaba que desde la época flavia se había impuesto una cierta regulación en el sentido de que el tribunado militar se consiguiese después del vigintivirato. Para este último cargo ocupado después del desempeño del tribunado de una legión ver D. Mc ALINDON, "Entry to the Senat in the Early Empire", JRS., 48, 1958. pág. 322.

${ }^{5}$ G. Alfolor, Fasti..., obra citada, pág. 129; J.M. Roldán, El ejército..., obra citada,

${ }^{6}$ G. AlfÖldY, Fasti..., obra citada, pág. 128 not. 19 sugiere esta procedencia porque en el norte de Italia está testimoniado el nombre personal "Moccius". Del radical de este nombre procedería por derivación "Mocconius". Para la carrera de este personaje ver Prosopographia Imperii Romani, M.465; E. Groag, Die römischen Reichsbeamte ..., obra citada, págs. 101 y s.; A. Stein, Die Legaten von Moesien. Budapest 1940, pág. 43, not. 2.

' Los cargos a los que tenian acceso los miembros de la clase senatorial estaban jerarquizados y sometidos como el resto a determinados requisitos legales respecto a la edad requerida para ocuparlos y respecto al intervalo temporal que debía de mediar entre la magistratura que se dejaba y el desempeño de la siguiente: Digesto $L .4,14,5$ "no hay carencia de orden en el desempeño de los cargos, sino que tiene uno determinado, pues nadie puede desempenar primero un cargo superior sin haber desempeñado antes otro inferior, ni puede desempeñarse a cualquier edad ni puede prorrogarse". Ver también Dión Casio, LII,20.
} 
carrera senatorial comenzaba con la cuestura que daba acceso al senado. Para ocupar esa magistratura se requería tener la edad mínima de veinticinco años. De los diversos tipos de cuestura que había ("quaestor pro praetore», "quaestor urbanus», "quaestor principis» o "Augusti», "quaestor consulum»), Caius Mocconius Verus ocupó el cargo de “quaestor urbanus», que venia a ser como una especie de tesorero del senado. Pero antes de llegar a esta magistratura se exigía el haber ocupado otros cargos menores. Generalmente, los miembros de la clase senatorial lo hacian desempeñando uno de los puestos de los cuatro colegios en los que estaba dividido el vigintivirato ( $X$ vir stlitibus iudicandis, III vir kapitalis, III vir auro argento aere flando feriundo y IV vir viarum curandarunt) para luego seguir con un tribunado laticlavio en una legión. Son, no obstante, varios los casos como el de Caius Mocconius Verus en los que su carrera senatorial se inició con el desempeño del cargo de "tribunus laticlavius" para luego seguir con el vigintivirato, en este caso el de III vir capitalis", es decir, el de auxiliar de los magistrados que ejercen jurisdicción ${ }^{8}$.

El «tribunus laticlavius» era de rango superior al "angusticlavius» ${ }^{9} y$ por eso era el encargado de sustituir al legado de la legión ${ }^{10}$. El «tribunus laticlavius» disponía de un "officium» del que formaban parte once “beneficiarii»" ${ }^{11}$, posiblemente un “cornicularius"y, quizá, también otros funcionarios.

2.1. Después de la cuestura Caius Mocconius Verus ocupó el cargo de "tribunus plebis", del que estaban dispensados los ciudadanos patricios. Esto es un indicio más del bajo origen social que dentro de la clase senatorial tuvo este personaje que, además, muestra una carrera admi-

${ }^{8}$ En situación parecida en la que el tribunado precede al vigintivirato puede mencionarse entre otros los casos de CIL, II, 1262; III, 429, 6813, 14387. Las obligaciones del “tribunus militum" se encuentran señaladas en el Digesto XLIX, 16, 12, 2: “los tribunos militares y los jefes del ejército deben mantener a los soldados dentro de la estancia del campamento, conducirlos a los ejercicios de adiestramiento, tener en buen recaudo las llaves de las puertas, hacer de vez en cuando el recorrido por los puestos de vigilancia, cuidar la comida de la tropa, estar alerta respecto del suministro, evitar los fraudes de los proveedores, castigar los delitos con arreglo a la competencia correspondiente. frecuentar las salas de mando, escuchar las quejas de la tropa y realizar visitas de inspección a los enfermos". La duración del servicio era normaimente de un año. No faltan testimonios epigráficos en los que miembros de la clase senatorial han tenido dos tribunados (entre otros los casos de CIL, II, 1262; III, 10471-10473).

"El tribunado "laticlavius" tenía importancia mayor que el "angusticlavius" ver al respecto CIL, VIII, 18078.

${ }_{10}$ Ver CIL, X, 4749: tribun(us) milit(um) pro legat(o).

"Ver al respecto CIL, VIII, 2551. 
nistrativa lenta en la que apenas fue utilizado y que, por otra parte, si atendemos al hecho de que no fué propuesto para ningún cargo pretoriano, parece que debió de alcanzar la pretura - que se podía ya obtener a la edad de los treinta años- un poco antes de su muerte, acontecida a los treinta y seis años de edad.

3. El censo realizado por Caius Mocconius Verus se hizo sobre un conjunto de ciudades vasconas y várdulas. La cifra que indicaba el número de ciudades implicadas en el censo estaba, a lo que parece, incompleta. Dada la secuencia numérica percibida: XXIII, la laguna existente sólo es susceptible de completarse con una unidad, lo que daría una cifra total de veinticuatro “civitates". La inscripción no sólo no indica los nombres concretos de las ciudades en las que se ha realizado el censo sino que ni siquiera establece la proporción numérica de ciudades vasconas y várdulas que concurren en esa cifra global.

3.4. Para establecer dicha proporción D. Detlefsen tomó como punto de referencia la información que Plinio proporciona en el sentido de que a los Várdulos pertenencian XIIII populi ${ }^{12}$ para deducir, hipotéticamente, por eliminación, que el número de "civitates" vasconas implicadas en ese censo no eran más de nueve o diez según se completase o no la lagura con una unidad ${ }^{13}$.

Pero de los XIIII populi de los Várdulos aludidos por Plinio (quien utiliza el término "populus" desde el punto de vista administrativo para designar sobre todo unidades administrativas con un soporte urbano), éste sólo menciona a uno: "de los cuales basta con citar a los Alabanenses". Uno podría preguntarse si a la altura temporal en la que probablemente tuvo lugar el censo, época de Adriano (117-138) o de Antonino Pio (138-161), siguieron manteniéndose sin alteración, sin procesos de absorción, atribución a otros pueblos o desaparición, tantas "civitates" várdulas como pueblos había atribuido Plinio. Ptolomeo que redactó su obra por las fechas en las que parece que tuvo lugar ese censo (Ptolomeo floruit 127-148), y que acostumbra a dar bastantes nombres de ciudades, las que señala entre los Várdulos no pasan de siete (14). En cualquier caso, puesto que la inscripción no alude ni siquiera a la proporción numérica de ciudades vasconas y várdulas que sufrieron el censo, poca validez operativa puede tener el asumir como punto de partida los

12 PLINIO, N.H., III, 26: in Cluniensem conventum Varduli ducunt populi XIIII.

${ }^{13}$ D. DETLEFSEN, «Die tarraconensische provinz..., obra citada, pág. 643: Danach würde sich die zahl der civitates der Vasconen, die Plinius nicht angiebt, falls in diesen verhältnissen inzwischen keine veränderung eingetreten, auf 9 oder höchstens 10 belaufen haben. 
catorce «populi» várdulos aludidos por Plinio, pensar que todos estos fueron los que sufrieron el censo por parte várdula y atribuir a los Vascones el pico de nueve o diez ciudades necesarias para completar la cifra global que proporciona la inscripción.

3.2. Proceder de esta manera a partir de una expresión tan general como la de XXIIIII] civitatium Vasconum et VarduI(I)orum, parece un tanto inadecuado. Esta manera de operar asumiría cierta validez indirecta en el caso de que las ciudades vasconas conocidas por menciones en las fuentes de información no rebasasen la cifra que hipotéticamente se establece a la hora de explicar la proporción que pudieron concurrir en el censo. Pero no hay tal cosa. Cuando Plinio es su Naturalis Historia describe el "conventus caesaraugustanus", al señalar la cifra total de comunidades que concurrían en el mismo, utiliza también el término "populus: recipit populos LV». A continuación menciona el nombre de algunas comunidades indicando la situación jurídica de que disfrutaban. Pero no hace ninguna indicación no sólo ya respecto al grupo étnico al que pudieran pertenecer esas comunidades concretas mencionadas, sino ni siquiera, como hace en el caso de los Várdulos adscritos al "conventus cluniensis", con relación a la cifra numérica que pudiera corresponder a cada grupo étnico de los que concurren en el "conventus caesaraugustanus". Solo a través de otras fuentes y testimonios conocemos las ciudades que eran vasconas. Asi de las señaladas por Plinio sin especificar que fuesen vasconas, sabemos que lo eran doce de ellas ${ }^{15}$. Si a estas añadimos Oiasuna, mencionada por Estrabón ${ }^{16}$ como vascona, su número se elevaria, al menos, a trece. Parece, por tanto, poco probable

${ }^{14}$ Ptolomeo Geographia, II, 6, 66: Gebala, Gabalaika, Toulonion, Alba, Segontia Paramika, Trition Touborikon, Thabouka.

is Plinio, N.H., III, 3, 24: Caesaraugusta colonia immunis, amne Hibero adfusa, ubi oppidum vocabatur Salduba, regionis Edetaniae, recipit populos LV: ex his civium romanorum... Calagurritanos qui Nasici cognominatur... Latinorum veterum Cascantenses, Ergavicenses, Graccurritanos... foederatos Tarracenses; stipendiarios... Andelonenses, Aracelitanos... Carenses... Iluberitanos, laccetanos... Pompelonenses, Segienses por citar las ciudades vasconas.

${ }^{16}$ Por Estrabón $(I I, 4,10)$ sabemos que Oiasouna era vascona: "a través de estos lugares el camino que va desde Tarraco hasta los últimos Vascones próximos al Océano, los del área de Pompelon y los de la ciudad de Oiasouna". El padre Germán de Pamplona ("Los límites de la Vasconia hispanorromana y sus variaciones en la época imperial", IV Symposium de Prehistoria Peninsular, Pamplona, 1966, págs. 207-221) pensaba que esa ciudad pertenecia a los Várdulos y que luego pasó a manos vasconas. Su apoyo para esta suposición se basa en la información proporcionada por Mela $(I I I, 15)$ en el sentido de que los Várdulos como pueblos se extendian hasta el Pyrenaei iugi promuntorium. En cualquier caso se trata de una cuestión que debería remitirse a las fuentes que inspiraron a Estrabón y a Mela sus respectivos pasajes. 
que para la época de Plinio pudiera cifrarse en nueve o diez el número de ciudades vasconas. Menos aún, por tanto, cabe suponer esa cifra para la época en la que se propone situar dicha inscripción. Ptolomeo, cuya existencia se desarrolla en esa época propuesta, menciona dieciséis comunidades vasconas, que unidas a los Aracelitani, Carenses e lluberitani —que él no menciona, pero sí Plinio-, y que sabemos que estaban incluidas dentro del territorio vascón ${ }^{17}$, elevarian a diecinueve, al menos ${ }^{18}$, el número de comunidades vasconas susceptibles de recibir el susodicho censo.

3.3. El territorio vascón, que inicialmente ocupó un espacio geográfico inferior al que posteriormente le atribuyen las fuentes grecorromanas, se benefició de una expansión territorial a expensas de otros pueblos limítrofes.

Es Ptolomeo, como hemos indicado, el que menciona como vasconas comunidades que en unos casos sabemos que pertenecian anteriormente a otros pueblos y en otro lo sospechamos. Pero de esta circunstancia no podemos deducir que, puesto que Ptolomeo vive en la misma época en la que se sitúa cronológicamente la inscripción, el censo pudiera ser exponente del reajuste fronterizo subsiguiente a esa expansión territorial. No parece que nada de esto haya tenido lugar en esta época. $Y$ esto porque, por un lado, el expansionismo señalado afectó preferentemente al sector oriental y meridional del territorio vascón, y, además, todo parece indicar que éste tuvo lugar en fechas anteriores ${ }^{19}$;

"Si tenemos en consideración la semejanza toponomástica entre los "Aracelitani" de Plinio, la "mansio Aracaeli" del Itinerario Antoniniano y los actuales Araquil, rio, y Huarte Araquil, villa, es muy probable que la comunidad mencionada por Plinio estuviese por esa zona. Respecto a los "Carenses", no sólo hay una continuidad en el nombre con la actual villa navarra de Santacara sino que los materiales exhumados en la misma se remontan a la época de la Edad del Hierro y se continúan en la romana (M. A. MEzouiriz, "Primera campaña de excavaciones en Santacara (Navarra)", P.V., 138-139, 1975, pág. 84 y págs. 106-109). Respecto a los "lluberitani", cuyo lugar de ocupación se acostumbra a identificar con la actual Lumbier, no hay testimonios por ahora de la Edad del Hierro, pero sí de época romana (B. Taracena y L. Vázquez de Parga, "Romanización", P.V. 7, 1946, pág. 431; para ese mosaico encontrado en ese lugar ver $\mathrm{J}$. M $\mathrm{M}^{\mathrm{a}}$ Blázquez y $\mathrm{M}^{\mathrm{a}}{ }^{\mathrm{A}} \mathrm{A}$. Mezquiriz, Mosaicos romanos de Navarra. Madrid 1985, pág. 52, núm. 32.

18 Ptolomeo, II, 6, 67 menciona como vasconas las comunidades siguientes: Itouris(s)a, Pompelon, Bitouris, Andelos, Nemantourisa, Cournonion, lakka, Gracouris, Kalagorika, Kaskonton, Ergaouia, Tarraga, Mouskaria, Setia. Alauona. En II, 6, 10 menciona, además, a Oiasso.

${ }^{19}$ Los acontecimientos históricos a consecuencia de los cuales se propició, tal vez, la expansión vascona en esas zonas, han sido estudiados por G. FATAS ("Sobre Suessetanos y Sedetanos", AEA, 44, 1971, págs. 109-125; Ídem, "La Hispania entre Gatón y Graco", HA. 5, 1975, págs. 269-313; İdem, "Aproximación al estudio de la expansión vascona en 
$y$, por otra lado, porque la porción del territorio actual navarro que forma límite con las tierras alavesas ocupadas por Várdulos, han proporcionado en ambos lados provinciales un conjunto de inscripciones, de semejanza estilística y onomástica, que todavía nos mantiene en la incertidumbre a la hora de atribuírselo a uno u otro pueblo ${ }^{20}$. Si por ese sector occidental vascónico hubo ampliación territorial a favor de los Vascones, es algo que desconocemos. Únicamente en la zona de Oiasuna se sospecha con claridad relativa no exenta de problemas, una posible ampliación territorial vascona en detrimento de los Várdulos. De existir tal ampliación corresponderia, innegablemente, a una época anterior a la que se sitúa la inscripción en cuestión.

4. El censo se realizaba en Roma desde antiguo ${ }^{21}$. Su importancia fue en aumento porque suponía una revisión periódica de los ciudadanos y de sus obligaciones militares y fiscales. En Roma, además, los "censores" asumían el control de las costumbres mediante la "nota censorial», que se realizaba con el censo ${ }^{22}$. Desde el punto de vista temporal, los censos, en las últimas etapas de la República, se hicieron con una gran irregularidad. Con Augusto los censos alcanzan un notable impulso ${ }^{23}$.

los siglos II y I a.C.", La romanización del Pais Vasco. Estudios de Deusto, 1972, pág. 389).

${ }^{20}$ Para estas cuestiones en esa zona fronteriza ver J.J. SAYAS ABEngochea ("De Historiae Vasconiae rebus controversis", Ponencias Primer Congreso General de Historia de Navarra, P.V. Anejo 6. Pamplona 1987, págs. 103-109).

21 La tradición romana atribuye a Servio Tulio la elaboración del censo (Tiro Livio, I, 42,4-44. La creación de la censura en el 443 (Tito Livio, IV, 8, 2: Idem hic annus censurae initium fuit, rei a parva origine ortae) se considera como una reacción patricia (STAVELEY, "The Significance of the consular Tribunate". J.R.S., 43, 1953, pág. 30). La censura se fue difuminando con la República. César asumió la potest censoria vitalicia, sin colega. Los censos del 8 a.C. y del 14 d.C. los hizo Augusto actuando "consulari cum imperio". En el 74. Vespasiano asumió la censura a perpetuidad y lo mismo hace Domiciano en el 85. Para los censos de época republicana ver G. PIERI, L'histoire du cens jusqu'à la fin de la repúblique romaine. Paris 1967.

${ }_{2 z}$ CICERON. De Leg.,3. 3, 7 "censores... more populi regunto". Schmäling, Die Sittenaufsicht der Censoren. Stuttgart. 1938.

${ }^{23}$ SUETONIO, (Augusto, 27) señala que Augusto realizó por tres veces el censo: "ordenó por tres veces el censo del pueblo, la primera y tercera con un colega, la segunda solo". Y en la Res Gestae divi Augusti $(8,2 ; 8,3$ y 8,4$)$ se alude respectivamente a estos tres censos del 28 a.C., 8 a.C., y 14 d.C., y a los colegas con los que estuvo asociado en el cargo. Para el censo del 28 a.C., ver, además, DIÓN CASIO (L II, 42; L III, 1; y CIL, IX 4220 El censo del 8 a.C., no se conoce por otra fuente. Para el censo del 14 d.C. ver Suetonio (Augusto, 97 y Tiberio, 21). En otro orden de cosas, resulta una cuestión problemática saber si en época de Augusto hubo un censo general del Imperio, como sugiere el evangelista San Lucas (II, 1) o si, por el contrario, se realizaron censos separados en determi- 
Los censos se realizaron también en las colonias y los municipios. En algunas provincias estos censos locales se remontan incluso a una época republicana ${ }^{24}$. Los magistrados de estas comunidades locales cuando coincidían con el año en el que se realizaba el censo local, se conocian con el nombre de "quinquennales". Hacian los censos contabilizando a los ciudadanos ${ }^{25}$ y registrando la riqueza, propiedades que tenían y sus características ${ }^{26}$ por cuanto que todo ello suponía la base del sistema tributario. Estos censos locales, elaborados por los magistrados jurídicamente competentes, estaban a disposición de los "censitores", "procuratores", "legati», etc. "ad census accipiendos", que eran los que tenian la responsabilidad sobre toda la provincia.

4.1. Por lo que respecta a los censos provinciales ya Augusto los realizó en las Galias ${ }^{27}$, que fueron seguidos de otros en épocas posteriores. La implantación de los censos provinciales resultó más fácil en aquellas provincias en las que el desarrollo urbano estaba consolidado y gozaban de la infraestructura básica adecuada.

nadas provincias como opina $H$. BraunEt («Der römische Provinzialzensus und der Schatzungsbericht des Lukas-Evangeliums", Historia, 1957, 192).

${ }^{24} \mathrm{La}$ "lex Rupilia", que concedia a las ciudades de Sicilia cierta autonomia, introdujo el censo quinquenal romano (ver CICERON, Verrin., 2, 131). Lo mismo debió de ocurrir con la "lex Pompeia" con relación a Bitinia, cuyos censos los realizaban magistrados especiales, "timetai" (PLINIO, Ep., X, 112, 113. Ver A.N. SHERWIN-WHITE, The Letters of Pliny. A Historical and Social Commentary, Oxford, 1966, pág. 672). La Tabula Heraclensis (circa 45 a.C.) indica, por su parte, que los censos los realizaban los magistrados supremos locales. Para el caso de Bitinia ver, no obstante, A.N. SHERWIN-WHITE..., obra citada, págs. 672-3.

${ }^{25}$ La Tabula Heraclensis, vulgo lex lulia municipalis (S. Riccobono, Fontes luris Romani Antejustiniani. Pars Prima. Leges, Florencia, (1941), 1968, pág. 151, 142-158 señala el procedimiento a seguir en la elaboración de los censos municipales en los que se debe indicar el nombre completo, la edad y el montante de la riqueza.

${ }^{26}$ Digesto, L, 15,4: "Está estipulado en las normas del censo que los campos se censen de la manera siguiente: el nombre del fundo en cuestión, la ciudad y el lugar en el que se encuentra, los dos vecinos limítrofes al fundo en cuestión, la cantidad de siembra que ha tenido en los diez años últimos, las yudas, el número de cepas de los viñedos, las yugadas que tienen los olivares y número de olivos, lo cosechado en el prado en los diez últimos años y número de yugadas que tiene, las yugadas de pastos y las de bosques... Respecto de la declaración de los esclavos, debe tenerse en cuenta la especificación de su origen, edad, oficio. Los propietarios están obligados a declarar los lagos de pesca y los puertos los mismo que las salinas si las hay en sus predios".

${ }^{27}$ Para los censos de las Galias en tiempos de Druso, Germánico, Nerón, Domiciano, ver respectivamente T. Livio, Per.,138;139; TACito, Ann.,I, 31; II, 6; XIV, 46; Front., Strag., 1, 1, 8. Para el resto de las provincias ver J. MARQuaRd, Handbuch der röm. Altertümer. Römische Staatsverwaltung, 2, pág. 213; E. GROAG, R.E., IV, A 842 s:, F. DE MAR. TiNo, Storia della costituzione romana, vol. IV. Nápoles 1975, págs. 917 ss. 
De ordinario era el gobernador, mediante un encargo especial, el responsable de realizar el censo. En las inscripciones se alude a este encargo como si se tratara de un honor ${ }^{28}$. En otras ocasiones, eran personas del orden senatorial, sin que falten tampoco miembros del orden ecuestre, los encargados de realizar el censo ${ }^{29}$.

La relación del censo ("formula censualis») provincial, que incluia la relación de las personas, además de todos los detalles de las tierras cultivadas, riquezas y esclavos poseidos, pues de todo ello se precisaba información para establecer el "tributum soli» y el "tributum capiti», es posible que quedase registrado en un archivo en la capital de la provincia ${ }^{30}$. Con sede en la capital de la provincia, Lusitania tenía también un archivo central atendido por personal específico, generalmente libertos imperiales ${ }^{31}$.

4.2. Para el censo general de la provincia se disponia de los datos proporcionados por los censos municipales. Pero no era infrecuente que la provincia, en función del censo, se dividiese en distritos menores. $Y$ es precisamente con estos distritos menores con los que guarda relación más directa el censo realizado por $\mathrm{C}$. Mocconius Verus. $\mathrm{Y}$ así, además de las inscripciones que hacen alusión a un censo general provincial, hay otras que aluden a circunscripciones menores. En un caso testimoniado

${ }^{28} \mathrm{La}$ inscripción $\mathrm{CIL}, \mathrm{II}, 4121$ nos indica que Q. Hedius Rufus Lollianus Gentianus no sólo fue gobernador y "censor provinciae Lugd(unensis), ítem Lugdunensium" y gobernador de la Tarraconense en época de Septimio Severo, sino que, además, realizó el censo de esa provincia: leg(atus) Aug(ustorum) prov(inciae) H(ispaniae) C(iterioris), fitem censit(or) $H$ (ispaniae) C(iterioris).

${ }^{29}$ Para Hispania, respecto a esas personas encargadas de realizar el censo se tiene testimoniado el caso de Q. Plotius Romanus (CIL, VI, 332), nombrado "legatus Augusti censibus accipiendis Hispaniae Citerioris", en un tiempo anterior, quizá, a Septimio Severo; el caso de C. Mocconius Verus (CIL, VI, 1643), nombrado cat census accipiendos civitatium XXIIII Vasconum et Vardullorum" y el de T. Clodius Proculus ( $C I L, X, 680$ de época julioclaudia) nombrado "leg[atus a..] Caesare Aug[usto missus pro] censore ad Lus[itanos]». Fuera de Hispania Q. Aemilius Secundus (I.L.S., 2683), que ocupaba el cargo insignificante de prefecto de una cohorte, llevó a cabo el censo de Apamea.

${ }_{30}$ Dada la relación existente entre los datos que de cada ciudad proporciona el censo y los impuestos fijados a través de ellos, es posible que este archivo formara parte del "tabularium censuale", caja provincial recordada en una inscripción de Tarragona (CIL, II, 4248), en la que C. Valerio Arabino es recordado como "sacerdos Romae et Augusti" y se le levantó una estatua ob curam tabulari censualis fideliter administr(atam).

${ }_{31} \mathrm{M}$. Ulpius Augusti libertus Gresianus (CIL, II, 3225), además del cargo de "tabularius" de la $X X$ hereditatium, de la provincia Lugdunensis y de Aquitanica, lo fue también de la provincia de Lusitania. De la capital de la provincia, Mérida, proceden las inscripciones de P. Aelius Aug(usti) lib(ertus) Alexander (CIL, II, 486), que fue "tabul(arius) provinc(iae) Lusitaniae" y de "P. Aelius Vitalis Aug(usti) lib(ertus)" (CIL, II, 485), que fue "tabul(arius) provinc(iae) Lusitaniae et Vettoniae". 
esta circunscripción la asume la unidad político-administrativa representada por el "conventus", concretamente el "caesaraugustanus» ${ }^{32}$. En este sentido, sería preciso tener presente que los Vascones en cuanto que constituian uno de los grupos étnicos que integraban dicho "conventus" -no así los Várdulos que pertenecían al Cluniense - se verian implicados en el censo realizado sobre el "conventus caesaraugustanus". $Y$ aunque fuera de esta cita nos falta información pertinente respecto de si el "conventus" siguió funcionando como distrito censual regular menor, dado que el "conventus" era una unidad político-administrativa consagrada, es verosimil que así lo fuera con preferencia a otros, esporádicos quizá, y motivados por exigencias circunstanciales que se nos escapan.

En este último contexto, debe incluirse, suponemos, el censo realizado sobre veinticuatro ciudades vasconas y várdulas. Se ha opinado que a la hora de establecer las circunscripciones censuales menores del censo provincial, se tuvieron también en cuenta las unidades étnicas y los distritos de reclutamiento en cuanto que el censo, al contabilizar además de la riqueza a las personas, en cierta manera guardaba relación con el reclutamiento voluntario o con la leva ${ }^{33}$. Pero afinidades étnicas y culturales aparte, que, por otro lado, parecen hundir sus raices en épocas pretéritas, el hecho es que Várdulos y Vascones son considerados por los romanos como dos pueblos distintos y, además, adscritos por ellos a conventus diferentes, "Cluniensis" y "Caesaraugustanus". Incluso en el terreno organizativo del ejército romano, que, como sabemos, contaba con unidades militares proclives a mantener el étnico originario aun cuando hayan sido trasladadas lejos de su patria de origen y acuarteladas en otros lugares del Imperio, puede apreciarse que Vascones y Várdulos configuraron unidades separadas: "cohors I Fida Vardullorum civium Romanorum" para los Várdulos y "cohors I Vasconum civium Romanorum" para los Vascones ${ }^{34}$. No vemos, por tanto, la razón para que Várdulos y Vascones constituyan un distrito censual regular dentro de la provincia Tarraconense a la que indudablemente pertenecían am-

${ }^{32} \mathrm{CIL}, \mathrm{VIII}, 7070 \ldots$ ionius... censitor conventus Caesaraugusta ni.

${ }^{33}$ En este sentido se dispone de algunos indicios al respecto. Asi en la provincia Narbonense, de manera general, el censo provincial fue seguido de la leva (O.H., 6453). Y respecto a la Lusitania, no estamos en condiciones de establer $-\mathrm{y}$ no sólo a causa de la mutilización de la inscripción-, si la misión censual realizada por $T$. Clodius Proculus $(\mathrm{ClL}, \mathrm{X}, 680)$ afectó únicamente a los lusitanos con exclusión de los otros pueblos que concurrian en la división administrativa de la provincia de Lusitania, o si por extensión se incluia a toda la provincia.

${ }^{34}$ Ver J.M. Roldan, Hispania y el ejército romano. Salamanca 1974, págs. 143-145; págs $129-130$ y pág. 145 , respectivamente. 
bos pueblos. $Y$ a esta conclusión llegamos porque por una parte los Vascones pudieron o debieron ser censados en su "conventus" correspondiente (véase nota 32) y, por la otra, con arreglo a la inscripción (CIL,VI,1643) lo fueron formando grupo con los Várdulos. Lo que nos sugiere es que el censo realizado por Caius Mocconius Verus fue de carácter circunstancial y limitado por cuanto que sólo afectó a XXIII o XXIIII ciudades de Vascones y Várdulos cuando sabemos que el número global de ciudades pertenecientes a ellos era superior.

4.3. Ciertamente desconocemos el motivo concreto que aconsejó realizar el censo sobre estas ciudades. Como ya hemos indicado no parece adecuado pensar - aunque tampoco resultaría muy improcedente por cuanto que de varias ciudades vasconas sólo sabemos que eran vasconas porque nos lo dice Ptolomeo cuyo período vital coincide con la época propuesta para la inscripción-- que se deba a una ampliación territorial vascónica o a problemas territoriales entre ambos pueblos. Tampoco parece que sea consecuencia de la necesidad de atender a la progresiva adquisición de algunas "civitates" de un estatus privilegiado, después del impulso que en este sentido comportó la concesión por Vespasiano del ius latii universae Hispaniae ${ }^{35}$. Pero la concesión generó un proceso progresivo de promoción que afectó a otras muchas "civitates" de Hispania y en manera alguna fue exclusivo de las vasconas y várdulas. No parece, por tanto, que haya sido esta la causa.

Ignoramos, pues, ciertamente, cual fue el motivo concreto que originó este limitado censo sobre ciudades vasconas y várdulas. A falta de una hipótesis explicativa verosímil, podría ponerse en relación subsidiaria con el reclutamiento. Es cierto que las unidades militares que conservan el étnico várdulo y vascón se constituyeron con gentes pertenecientes a esos pueblos. Pero su reclutamiento fue muy anterior a la fecha en la que se sitúa la inscripción que alude al censo. Por otra parte, como las bajas producidas por licenciamiento o por cualquier otro motivo se acostumbraban a llenar con gentes originarias de las proximidades en las que estaban acuarteladas estas unidades, es muy probable que, aunque esas unidades militares conserven en su denominación el étnico várdulo y vas-

${ }^{35}$ Sobre las repercusiones en Hispania del "ius Latii" ver J.J. SAYAS ABENGOCHEA, "Municipalización de la Hispania romana. Ideologia y realidad", Centralismo y descentralización. Modelos y procesos históricos en Francia y en España. Madrid 1985, págs. 123-146. Ciertamente en la nómina de Plinio, anteriormente indicada, son pocas las ciudades, posteriormente conocidas como vasconas, que ofrecen un estatus privilegiado. Indudablemente lo irán alcanzando como una consecuencia de la concesión por Vespasiano del ius Latii universae Hispaniae. 
cón, sus componentes ya no fuesen, o lo fuesen en grado infimo, originarios de los pueblos aludidos con esos étnicos. Por esta razón, y aunque la mayoria relativa de los testimonios de soldados vascones que han servido en unidades militares del ejército romano parece situarse, poco más o menos, en las proximidades cronológicas de la época atribuida al censo, poco podemos avanzar al respecto por este camino.

En este sentido mayor significación alcanza para algunos - aunque muy relativa a nuestro parecer- la condición que tiene de militar el personaje que realiza el censo. No se trata del gobernador de la provincia que haya recibido ese encargo, ni de un ulegatus" nombrado ex profeso y sólo para eso, sino de un "tribunus laticlavius legionis VII Geminae", que sin dejar el cargo militar de la única legión instalada en Hispania, había recibido el nombramiento "ad census accipiendos" de veintitrés o veinticuatro ciudades vasconas y várdulas. Pero se trata, indudablemente, de una mera sugerencia que en modo alguno disipa la niebla que envuelve las cuestiones suscitada y derivadas de ese censo.

\section{B. LEGATIO CENSUALIS DE CAIUS CORNELIUS VALENS}

1. La inscripción honorífica dedicada al pamplonés Caius Cornelius Valens ${ }^{36}$ nos remite a una "legatio censualis". Este personaje era conocido por otra inscripción (que debió de formar parte de un pedestal) dedicada a su esposa Sempronia Placida, flaminica del culto imperial ${ }^{37}$. El culto al emperador que otorgaba la provincia estaba íntimamente relacionado con la asamblea provincial. Los componentes de ésta elegían a los "flamines" y "flaminicae" provinciales y decretaban entre otras cosas los honores a recibir por los sacerdotes y sacerdotisas del culto imperial

${ }^{36}$ La inscripción que A. Povillon vió en Tarragona en el 1585 y que describió en sus pautas generales está recogida por $E$. Hübner en CIL, II 4208 . El sabio alemán realizó ya algunas correcciones estableciendo la siguiente lectura: $C$ (aio) Cornelio /C(ai) fil(io)/ / Valentin/o / / Pompae /1/ onensi/ ob legationem / / clensualem gra /tuitam summopere gestam / sub imperatore / $p$ (rovincia) $H$ (ispania) $C$ (iterior). Esta lectura, corregida posteriormente gracias a un calco, está recogida también en M. Marchetti, Diz. Ep., III, 831 y por J. Deininger, Die Provinziallandtage der römischen Kaiserzeit von Augustus bis zum Ende des dritten Jahrhunderts n. Chr., Munich, 1965, pág. 127.

${ }^{37} \mathrm{ClL}$, II, 4246: Semproniae / Fusti f(iliae) Placidae / Pompaelonensi / flaminicae, con / sensu concili/ $P$ (rovinciae) H(ispaniae) C(iterioris) / $C$ (aius) Cornelius Valens / maritus / s(ua) p(ecunia) f(ecit). 
provincial que dejaban el cargo. En el caso de Sempronia Placida esta jurisdicción del "Concilium" provincial queda puesta de manifiesto en la inscripción mediante la expresión consensu concilii Provinciae Hispaniae Citerioris, aunque los gastos pecuniales derivados de la dedicación no fueron desembolsados por el "arca concilii», sino sufragados por su esposo "de sua pecunia", que es, precisamente, el que aparece como dedicante. Mas, generalmente, era el «concilium» provincial el que pagaba la mayor parte de las estatuas erigidas en honor de los "flamines" y uflaminicae" provinciales y consecuentemente era la provincia, en este caso la Citerior, la que en las inscripciones aparecía como dedicante.

1.1. Pero las deliberaciones y decisiones del "concilium" a la hora de conceder honores y eregir estatuas honoríficas no se circunscribian sólo al terreno religioso. Tratamiento análogo recibían otras personas, que sin ser sacerdotes o sacerdotisas, velaron por los intereses provinciales, beneficiaron a la provincia de diversas maneras o sacaron adelante los encargos encomendados por la asamblea provincial. Ob causas utilitatesque publicas fideliter et constanter defensas se lee en la inscripción, que debió de formar parte de un pedestal, que dedica la provincia de la Hispania Citerior en honor de Caius Annius Flavius ${ }^{38}$. Y este mismo honor recibe Caius Cornelius Valens por el desempeño de la "legatio" encomendada por la asamblea provincial. En la realización de esta "legatio", lo mismo que en la de Q. Caecilius Rufinus Saguntinus ${ }^{39}$, la asamblea provincial tenía motivos de agradecimiento no sólo por el éxito de la gestión, que implícitamente se sobreentiende, sino por haber corrido con los gastos derivados de la "legatio" como expresamente se especifica.

2. Esto nos lleva a considerar la facultad que asistia a las comunidades locales y a la asamblea provincial de enviar legaciones a otros lugares y personas, sobre todo ante el emperador y ante los órganos competentes por los motivos más diversos. Esta práctica tenía una gran tradición en el derecho de gentes pero también era una consecuencia de la cuota de autonomia que Roma dejó disfrutar a las comunidades locales no privilegiadas pero también a las que se configuraron como colonias y municipios. La costumbre de enviar «legationes" por los motivos

${ }^{38} \mathrm{CLL}$, II, 4192: C. Annio L. f. / Quir. Flavo / Mliobrigens. / ex gente Canta / brorum/ provincia Hispa / nia Citerior / ob causas utilita / tesque publicas / fideliter et con / stanter defensas.

${ }^{39} \mathrm{CIL}$, II, 4201: Q. Caecilio / Gal. Rufino / Q. Caecili/Valeriani f. / Saguntino ob / legationem qua / gratuita aput/ Maximum princ(ipem) / Hadrianum Aug(ustum) / Romae funct(us) est/P(rovincia) H(ispania) C(iterior). Para otra "legatio gratuita" ver CIL, II, 4057. 
más variopintos estuvo tan generalizada en la práctica administrativa que la normativa que les afectó ocupa un capítulo entero del Código de Justiniano.

La iniciativa en la propuesta de esas "legationes" la tomaban los dunviros, pero se sometía a la deliberación del senado municipal, presentes la mayoría de sus miembros, para que fuesen aprobadas con mayoría de votos ${ }^{40}$. La elección recaía frecuentemente entre los miembros del orden decurional como se pone de manifiesto en las inscripciones. Por su parte la lex Ursonensis indica que el elegido podía nombrar a un sustituto (vicario) entre los miembros del orden decurional ${ }^{41}$.

De manera análoga a las comunidades locales, los componentes de la asamblea provincial acostumbraban a elegir como embajadores a miembros pertenecientes a la misma. Cabe suponer que Caius Cornelius Valens lo haya sido. La inscripción nada dice respecto al "cursus honorum" seguido por este personaje ni respecto a los cargos político-administrativos que pudo desempeñar. Pero el hecho de que fuese designado por la asamblea provincial para la "legatio", que ésta corriese a sus costas, que también sufragase "de sua pecunia" y con el "consensu concilii» la dedicación honorífica a su esposa, todo esto sugiere no sólo que este personaje era miembro de la asamblea provincial, representando quizá a Pamplona de donde eran originarios él mismo y su esposa, sino que disponía de recursos económicos abundantes y gozaba de relaciones políticas y sociales suficientes como para influir en los miembros de la asamblea provincial.

${ }^{40}$ La lex Ursonensis, 92 (A. D'Ors, Epigrafía jurídica de la España romana, Madrid 1953, pág. 215 s.) dice: I/viri quicumque in ea colon(ia) magi(stratum) habebunt, ei de legationibus publice mittendis ad decuriones referunto, cum $m$ (aior) $p$ (ars) decurion(um) eius colon(iae) aderit, quotque de his rebus maior pars eorum qui tum aderunt constituerit, it ius ratumque esto.... Ni ita dederit, in res sing(ulas), quotiens ita non fecerit, $H S$ (sestertium) cci, colon(is) huisque col(oniae) d(are) d(amnas) e(sto), eiusque pecuniae cui volet petitio persecutioque esto. Con arreglo, pues, a la ley de Urso el designado tenia la obligación de cumplir la delegación encomendada bajo la amenaza, en caso contrario, de ser castigado con una multa de 10.000 sestercios cuantas veces hiciese tal cosa. También en el Digesto (L, VII, 1) se dice que si "el legado municipal se desentendiera de la legación será castigado, según se acostumbra, con la poena extraordinaria de su remoción del orden decurional".

${ }^{41}$ Lex Ursonensis, 92, (A. D'Ors, Epigrafía Juridica... obra citada, pág. 216): Quamque legationem ex $h(a c)$ l(ege) exve d(ecurionum) d(ecreto) quot ex $h$ (ac) l(ege) factum erit, obire oportuerit neque obierit qui lectus erit, is pro se vicarium ex eo ordine, uti hac lege de(curionum)ve d(ecreto) o(portet)dato. Sobre el vicario ver también Digesto (L., VII, 14(13) y sobre los hijos en sustitución del padre Digesto (L., VII, 5(4)). La inscripción CIL, II, 2132 alude a un decurión nombrado "legatus perpetuus" y la CIL, II, 5031 señala... decurioni Virunensium defuncto Romae in legationi. 
3. La inscripción de Caius Cornelius Valens, que E. Hübner conocía por las referencias escritas de Povillon (Povillon f. 26 servavit solus, dice Hübner), fue corregida en algunos aspectos por ese autor. Mientras la inscripción estuvo desaparecida, la "legatio censualis" de este personaje, a falta de una especificación más concreta, ofrecia algunas dificultades para su correcta interpretación. Así, bien se ponía en relación con la administración del "arca concilii», bien como una legación encargada de solucionar alguna cuestión suscitada referente al censo, bien con una posible petición de remisión de impuestos ${ }^{42}$.

Desde el siglo Xvi en que fue contemplada y anotada por Povillon la inscripción se dio por desaparecida hasta que en el 1965 se localizó empotrada en una casa de Tarragona. A partir del vaciado de yeso que se hizo, G. Alföldy pudo establecer algunas correcciones esenciales para la comprensión de la inscripción ${ }^{43}$. El "summopere", que se leía con anterioridad, resultaba que era Sirmi pro/s/pere y la nueva lectura la/put imperator(em) sustituía a la antigua sub imperatore, aunque también ahora la inscripción nos dejaba en ayunas respecto de qué emperador se trataba. Pero la nueva lectura aportada el dato de que la "legatio censualis" fue enviada a presencia del emperador, que se sabia que se encontraba en Sirmio. Esta circunstancia proporcionaba nuevas posibilidades de interpretación por cuanto que reducia el campo de referencia a aquellos emperadores que, por algún motivo, habian fijado su residencia en Sirmio. Las deducciones pertinentes al respecto le permitieron a $\mathbf{G}$. Alföldy proponer que la legatio censualis del pamplonés Caius Cornelius Valens se hizo ante el emperador Marco Aurelio, quien en la guerra contra los Sármatas, y durante un período comprendido entre el 172-175, tuvo su cuartel en Sirmio ${ }^{44}$. Esta propuesta la reforzaba con la conside-

${ }_{42}$ Asi E. Hübner (pág. 566) la ponia en relación con el «arca concilii». M. MARCHETI (Diz. Epig., III, pág. 831), atendiendo a la dificultad que para una consideración de este tipo ofrecia la autonomía que tenia la asamblea provincial en la administración de su caja, piensa más bien que se trataba de una embajada remitida para solucionar alguna cuestión relacionada con el censo. O. HIRSCHFELD (Die kaiserlichen Verwaltungsbeamten bis auf Diocletian, 2 Aufl. Berlín 1905, pág. 64, núm. 3) piensa, y en esto le sigue A. D'Ors (Epigrafia jurídica..., obra citada, pág. 139) que pudiera tratarse de una "legatio" peticionaria de remisión de impuestos.

${ }^{43}$ La lectura y las correcciones propuestas por G. ALFOLDY (Die römische Inschriften von Tarraco. Berlin 1975, pág. 332 y "Eine spanische Gesandschaft in Pannoniens", A.E.A., 43,1970, págs. $169-70$ y ss.) es la siguiente: C(aio) Cornelio / Valenti / Pompaelonensi / ob legationem/ censualem gra/ tuitam Sirmi pro/s pere gestam a put imperator(em)/ $P$ (rovincia) H(ispania) C(iterior).

${ }_{44}$ Para las cuestiones sobre quien era el emperador ante el cual tuvo lugar la legación, en qué época y qué circunstancias pudieron motivarla ver G. ALFOLOY, "Eine spanische Gesandschaft in Pannoniens", A.E.A., 43, 1970, pág. 169 ss. 
ración de que en los años inmediatamente anteriores las tierras de Hispania padecieron las invasiones moras ${ }^{45}$, 10 que obligó al traslado de la legio VII Gemina desde la Tarraconense a la Bética y a colocar estas provincias bajo un único mando a las órdenes de Caius Aufidius Victorius, legatus Au(gustorum) (pro praetore provinciarum Hispanial e Cite/riorils et Baeticae ${ }^{46}$.

Pudo parecer, por tanto, oportuno que, tras la situación anómala que vivió la Península y que motivó la adopción de medidas administrativas especiales para atajar el peligro moro, se tomaran las medidas necesarias para volver a la situación administrativa anterior, lo que quizá pudo suscitar, o se temía que suscitara, temores en distintos sectores de ambas provincias. El momento pareció oportuno a los miembros de la asamblea provincial de la Tarraconense para proceder a la realización de un censo y enviar la "legatio censualis" ante el emperador para notificárselo y para que de esta manera quedasen zanjadas las posibles cuestiones conflictivas entre ambas provincias o, si el censo todavía no había tenido lugar, para pedírselo exponiendo las cuestiones que el censo pudiera suscitar.

${ }^{45}$ La Historia Augusta (Vit. Marci, 21,1) y las inscripciones CIL, II, 1120 Y 2025, aluden a una invasión de gentes moras que afectó a una porción territorial amplia del suelo peninsular (Historia Augusta, Vit. Severi, 2, 4, para la Bética).

${ }_{46}$ Sobre los diversos aspectos relacionados con este C. Aufidius Victorius y la bibliografía al respecto ver G. ALFOLDY (Fasti obra citada, pág. $38 \mathrm{~s}$. Por lo que hace a $\mathrm{P}$. Cornelius Anullinus que sirvió en la "legio VII Gemina» durante esa invasión ver Fasti, obra citada, pág. 122 y s.).

De acuerdo con una inscripción aparecida en Roma y que se fecha por esa época se dice que L. lulius Velilius Gratus lulianus... praepositus vexillationis per Achaiam et Macedoniam et in Hispanias adversus Castabocas et Mauros rebelles... Se considera que acabó con la rebelión de los Castabocos de la zona de la Acaya a lo más tardar en el 170-171. Por lo tanto para esas fechas estaba en disposición de acudir a Hispania para atajar la invasión mora. Sobre esta invasión ver R. THOUvenot, "Les incursions des Maures en Betique sous le régne de Marc Auréle", R.E.A, 12, 1939; A. GARCIA y BELLIDO, "Las primeras invasiones moras en España", A.E.A., 8, 1955; E. GonZALBES, "Notas sobre la invasión de bereberes en la Bética en época de Marco Aurelio", Bibl. Esp. en Tetuán. 1976; J. M. ${ }^{a}$. BLAzquez, "Nuevo documento referente a la invasión de moros en la Bética en la época de M. Aurelio. Estado de la cuestión", Studi in onore di Gaetano Scherillo, II. Milán 1976. 